\title{
Endüstriyel Tesisler için Aktif ve Pasif Harmonik Filtre Uygulaması
}

\author{
Serhat Berat EFE* \\ Bitlis Eren Üniversitesi, Elektrik-Elektronik Mühendisliği Bölümü, Bitlis
}

\begin{abstract}
Özet
Kaliteli elektrik enerjisi arzı için, sağlanan enerjinin temel büyüklükleri olan akım ve gerilim dalga şekillerinin tam sinüzoidal olması gerekmektedir. Ancak güç sisteminde mevcut olan, yarıiletken teknolojisi temelli elemanlar başta olmak üzere birçok yükün doğrusal olmayan özellik göstermesi nedeniyle harmonik bozunum adı verilen dalga şekli bozulmaları ortaya çıkar. Bu çalışmada güç sistemlerinde ve endüstriyel tesislerde güç kalitesini bozan en büyük etken olan harmoniklerin analizi yapılmış, PSPICE ve MATLAB platformları kullanılarak tasarlanan pasif filtrenin 6- darbeli güç elektroniği çeviricisi üzerindeki, yine aynı platformlar altında oluşturulan aktif filtrenin 12- darbeli güç elektroniği çeviricisi üzerindeki etkileri incelenmiştir.
\end{abstract}

Anahtar Kelimeler: Harmonikler, Güç Kalitesi, PSPICE, MATLAB

\section{Active and Passive Harmonic Filter Application for Industrial Installations}

\begin{abstract}
Current and voltage waveforms, which are fundamental quantities of the supplied energy, have to be completely sinusoidal for supplement of high quality energy to customers. However, presence of especially semiconductor technology based equipment, which have nonlinear characteristics, causes waveform distortions that called harmonic distortion in power systems. In this paper, harmonic analysis, used to figure out harmonics, which are one of the major parameters that affect power quality adversely in power systems, is performed. Effects of passive harmonic filter on 6-pulse converter and active harmonic filter on 12-pulse converter are observed by using PSPICE and MATLAB platforms
\end{abstract}

Keywords: Harmonics, Power quality, PSPICE, MATLAB

\section{Giriş}

Güç sistemine bağlı kullanıcılara kaliteli bir elektrik enerjisi sağlayabilmek için; enerjinin sürekli olması, gerilim ve frekans değerlerinin sabit tutulması, güç faktörünün 1.0 değerine en yakın değerde bulunması, faz gerilimlerinin dengeli olması ve gerilimdeki harmonik miktarlarının belirli değerlerde kalması gibi bir takım ölçütlerin göz önünde bulundurulması gerekmektedir [1,2].

Bir elektrik güç sisteminin, güvenli ve sürekli halde çalışması için, sistemin tasarım ve işletme aşamasında bir takım etkenlerin göz önüne alınması gerekir. Bu etkenlerden biri de güç kalitesini belirleyen parametrelerden, lineer olmayan çalışma özelliğine sahip elemanların meydana getirdikleri harmoniklerdir [2]. Elektrik enerjisini üreten, ileten ve dağıtan kuruluşların görevi; kullanıcılara kesintisiz, ucuz ve kaliteli bir hizmet sunmaktır. Güç kalitesi kavramında amaç, sabit şebeke frekansında; sabit ve sinüzoidal biçimli uç gerilimidir. Şekil 1'de saf sinüs biçimli gerilim ifadesinin A, $\mathrm{B}, \mathrm{C}$ fazlarının gerilim işareti verilmiştir. [1].

\footnotetext{
*Sorumlu Yazar: sbefe@beu.edu.tr

Geliş Tarihi: 13.03.2016, Kabul Tarihi: 10.06.2016
} 


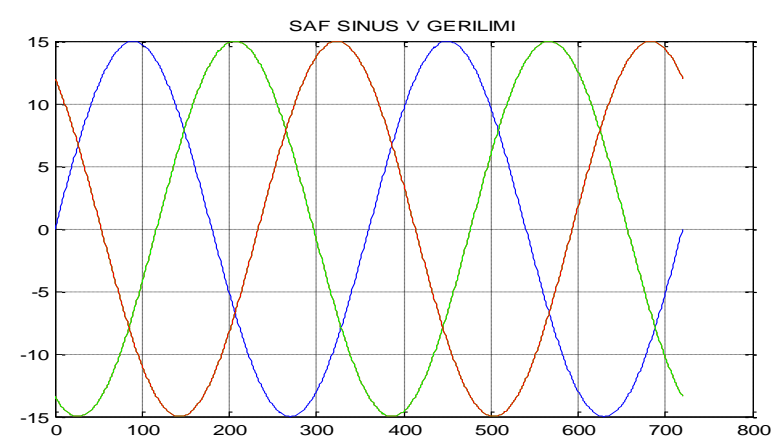

Şekil 1. A,B,C fazlarına ait saf sinüs biçimli gerilim işareti

Ancak pratikte böyle bir enerjinin sağlanabilmesi beraberinde bir takım zorluklar getirmektedir. Güç kalitesi problemlerinin en başında gelen sorunlardan birisi harmoniklerdir [3]. Harmonikler gerilim ve akım dalga biçiminin sinüs biçiminden uzaklaşmasına neden olan bozulmalardır [4]. Temel harmonik kaynaklarına örnek olarak güç elektroniği devreleri ve elektromekanik cihazlar verilebilir. Şekil 2'de harmoniksiz ve harmonikli gerilim işareti gösterilmiştir.
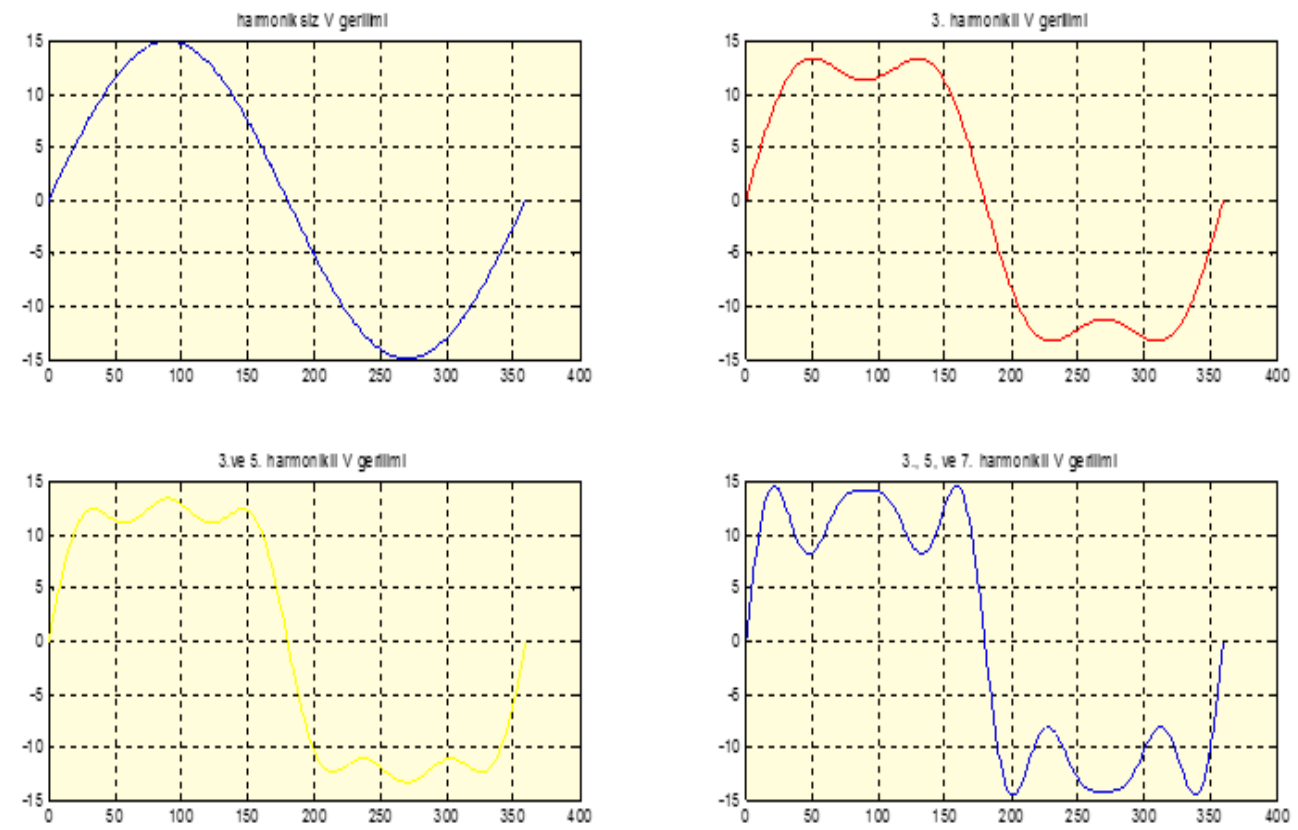

Şekil 2. Harmoniksiz ve harmonikli gerilim dalga şekilleri

$\mathrm{Bu}$ çalışmada bir pasif filtre uygulamasına bir de aktif filtre uygulamasına yer verilmiştir. Ayrıca MATLAB ve PSPICE ile harmonikli işaretin filtrelenmeden önceki benzetimi ile filtrelendikten sonraki benzetimi yapılarak sistemdeki mevcut harmonikler belirlenmiştir. Filtreden önceki ve filtreden sonraki benzetimler ve harmonik büyüklükler arasındaki fark analiz edilerek sonuçlar irdelenmiştir.

\section{Harmonik Kaynakları ve Etkileri}

Harmonikler genel olarak sistemde doğrusal karakteristik göstermeyen elemanların bulunmasından dolayı oluşurlar. Harmonik içeren akım ve ya gerilimin sistemde dolaşması sinüzoidal dalganın bozulması anlamına gelir ki bu da sisteme harmonik yayıp güç kalitesinin düşmesine ve devredeki 
elemanların zarar görmesine neden olur [5]. Ayrıca güç kalitesinin düşmesi tüketiciyi olumsuz etkiler. Başlıca harmonik kaynaklarına örnek olarak transformatörler, döner makinalar, güç elektroniği elemanları, kesintisiz güç kaynakları ve elektronik balastlar verilebilir.

Harmonikler genel olarak doğrusal olmayan karakterli elemanlar ile sinüzoidal olmayan kaynaklardan herhangi biri ya da ikisinin sistemde bulunması sonucu oluşurlar. Harmonikli akım ve gerilimin güç sistemlerinde bulunması, sinüzoidal dalganın bozulması anlamına gelir. Bozulan dalgalar sinüzoidal olmayan dalga olarak adlandırılır [6].

Harmonikler güç sistemlerinde ek kayıplar, ek gerilim düşümleri, rezonans olayları, güç faktörünün değişmesi gibi teknik ve ekonomik problemlere yol açar. Sinüzoidal alternatif akım uygulanan bir yükün şebekeden harmonikli akım çekmesi bu yüke ait yapısal bir özelliktir. Bu durum alıcının sürekli halde çalışması esnasında harmonik oluşturacak akım çekmesi anlamına gelmektedir. Bunların dışında, çalışma yapıları itibariyle doğrusal oldukları halde harmonikli akımlara yol açan alıcılar da vardır. Bu durum ise alıcıya uygulanan gerilimin sinüzoidal olmayan karakteri nedeniyle ortaya çıkmaktadır. Alternatif akımın üretilmesi sırasında generatörlerde gerekli önlemler alınarak elektrik enerjisi mümkün olduğunca sinüzoidal şekle yaklaştırılmaktadır. Ancak doğrusal karakterli bir yüke aynı şebekeye bağlı diğer doğrusal olmayan yüklerin etkisi olmaktadır [7].

Harmonikler, gerilim ve akım dalga şekillerinin bozulması, gerilim düşümünün artması, kompanzasyon tesislerinin zarar görmesi, enerji sistemindeki elemanlarda ve yüklerde kayıpların artması ve elektronik kart arızaları gibi çok çeşitli problemlere yol açmaktadır [8].

Şekil 3'te sistem içerisindeki doğrusal (lineer) ve doğrusal olmayan yüklerden sonraki akımgerilim işareti ve harmonik bileşenlerine ayrılmış işaret verilmiştir.

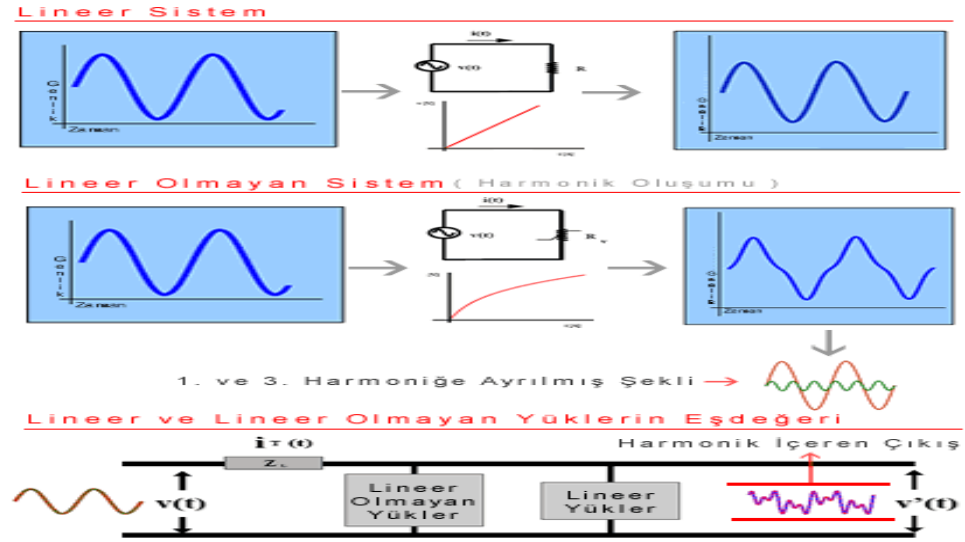

Şekil 3. Doğrusal ve doğrusal olmayan yüklerden sonraki akım ve gerilim işareti

Şekil 4'te harmonik bileşen içeren akım işareti görülmektedir

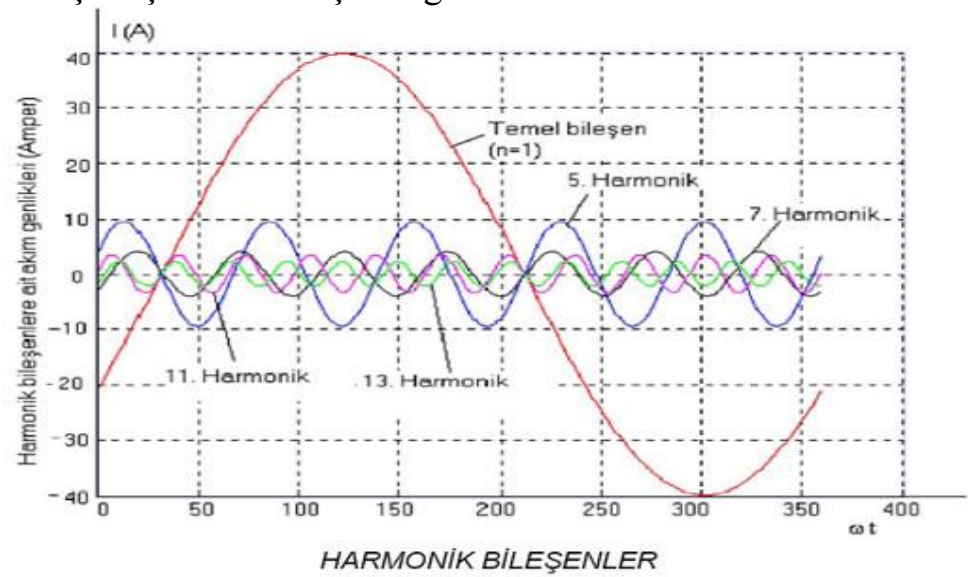

Şekil 4. Harmonik bileşen içeren akım işareti 
Böyle büyüklüklerin bulunduğu devrede aktif güç ifadesi,

$P=V_{0} I_{0}+\sum_{n=1}^{N} V_{n} I_{n} \cos (\delta n-\emptyset n)$

ile reaktif güç ise

$Q=\sum_{n=1}^{N} V_{n} I_{n} \sin (\delta n-\emptyset n)$

denklemi ile tanımlanır. Görünür güç,

$S=V I=\sqrt{\sum_{n=0}^{N} V_{n}^{2}} \cdot \sqrt{\sum_{n=0}^{N} I_{n}^{2}}$

eşitliği ile ifade edilir.

Harmonikli güç sistemlerinde tanımlanan diğer büyüklük bozunum gücüdür.

$S^{2}=P^{2}+Q^{2}+D^{2}$

ifadesinden bozunum gücü,

$D=\sqrt{S^{2}-P^{2}-Q^{2}}$

olarak belirtilir.

Bozunum gücü, harmonik bileşenlerin temel bileşene göre seviyesini belirlemek için kullanılır ve harmonik bozulmanın derecesini belirtir. Hem gerilim, hem de akım için verilebilir.

Gerilim toplam harmonik bozunumu

$T H D_{V}=\frac{1}{U_{1}}\left(\sum_{n=2}^{\infty} U_{n}^{2}\right)^{1 / 2}$

şeklinde ifade edilir. Akım toplam harmonik bozunumu

THD $D_{I}=\frac{1}{I_{1}}\left(\sum_{n=2}^{\infty} I_{n}^{2}\right)^{1 / 2}$

şeklindedir. Gerilim ve akımın harmonik içermesi halinde efektif değerlerini bulmak için bozunum faktörü kullanılır.

Akım için

$D F_{I}=\frac{1}{I}\left(\sum_{n=2}^{\infty} I_{n}^{2}\right)^{1 / 2}$

gerilim için,

$D F_{V}=\frac{1}{V}\left(\sum_{n=2}^{\infty} V_{n}^{2}\right)^{1 / 2}$

olarak ifade edilir.

\section{Harmoniklerin Filtrelenmesi}

Harmonikler nedeniyle oluşacak zararlı etkilerin engellenmesi sadece tasarımda alınacak tedbirlerle mümkün olmamaktadır. Harmonik akımların şebekeye geçmesini önlemek için ek devrelere ihtiyaç vardır. Devreye yerleştirilen ve istenen harmonik akımının süzülmesini sağlayan bu devrelere "harmonik filtresi " adı verilir. Harmonik filtrelerin amacı bir ya da daha fazla frekanstaki akım veya gerilimlerin yani harmoniklerin etkisini azaltmaktır. Harmonik filtrelerinin görevleri harmonik üreten bir cihazdan beslenen yükün gerilim dalgasını düzeltmek, AC sisteme katılan istenmeyen harmonik bileşenleri önlemek şeklinde özetlenebilir. İşlev bakımından filtreler ikiye ayrılır;

a) Filtrelerin kontrollü akım ya da gerilim kaynağına sahip olduğu "aktif" filtreler

b) Filtre bileşenlerinin direnç endüktans ve kondansatör gibi pasif elemanlardan oluşturulduğu "pasif" filtreler [1,2].

\subsection{Aktif Filtreler}

Harmoniklerin ortadan kaldırılması için geliştirilmiş elemanlardır. Bu filtreler ileri güç elektroniği temellerine dayanır ve pasif filtrelerden çok daha pahalıdır. Aktif filtreler birden fazla harmonik frekans1 için adreslenebilir ve enerji kalitesini etkileyen problemleri ortadan kaldırabilir. Aynı zamanda en önemli üstünlükleri mevcut dağıtımda değişiklikler yapıldığında bile etkili harmonik kompanzasyonuna 
devam edebilmeleridir. Aktif filtrenin çalışma prensibi, nonlineer yükün çekeceği temel bileşen dışındaki akımı karşılamaktır. Buna göre aktif filtreler yük tarafından çekilen harmonikleri analiz ederek harmonik bileşenleri uygun bir fazda yüke uygularlar. Şekil 5 'te aktif filtre ile harmoniklerin giderilmesi gösterilmiştir [1,2].

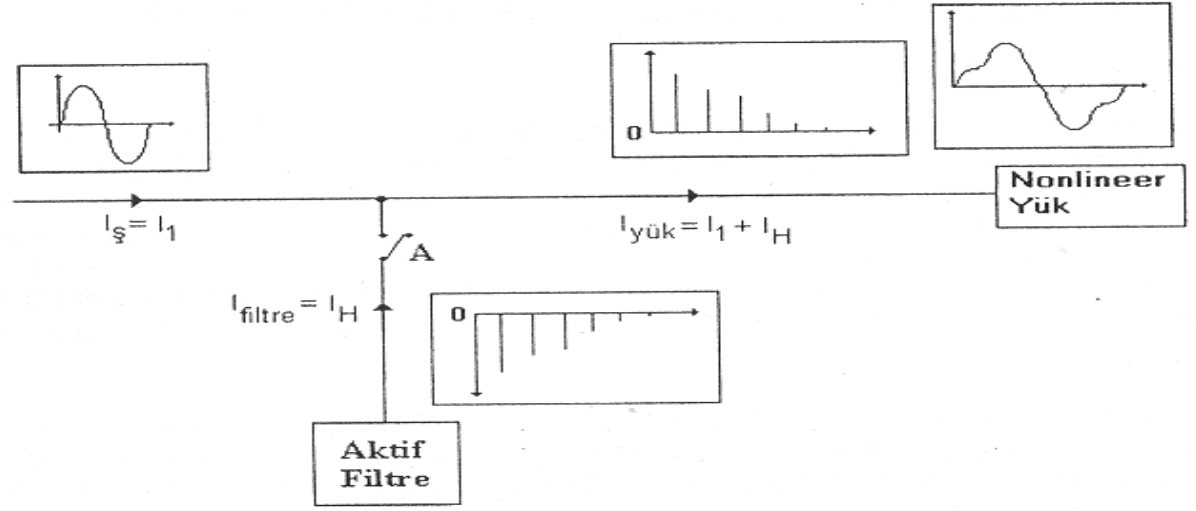

Şekil 5. Aktif filtre ile harmoniklerin giderilmesi

\subsection{Pasif Filtreler}

Pasif filtreler, kaynak ile alıcı arasına konulan ve temel frekans dışındaki bileşenleri yok eden seri bağlı kondansatör ve endüktans bileşimidir. Bazı durumlarda omik direnç de ilave edilebilir. Pasif filtrelerde amaç, yok edilmek istenen harmonik bileşen frekansında rezonansa gelecek L ve C değerlerini belirlemektir. Her bir harmonik bileşen için onu rezonansa getirecek ayrı bir filtre kolu gereklidir. Seri filtreler, harmonik kaynağıyla şebeke arasına seri olarak bağlanır ve harmonik akışına yüksek empedans gösterirler. Bu yüzden seri filtrelerin ayarlanmış olduğu frekansta yüksek empedans vardır. Paralel filtreler harmonik kaynağıyla şebeke arasına paralel olarak bağlanırlar. Bu tip filtrelerde amaç, düşük bir şönt empedans yoluyla istenmeyen harmonik akımlarının filtre üzerinden geçmesinin sağlanmasıdır. Paralel pasif filtrenin bir devreye bağlanışı şekil 6' da gösterilmiştir [1,2].

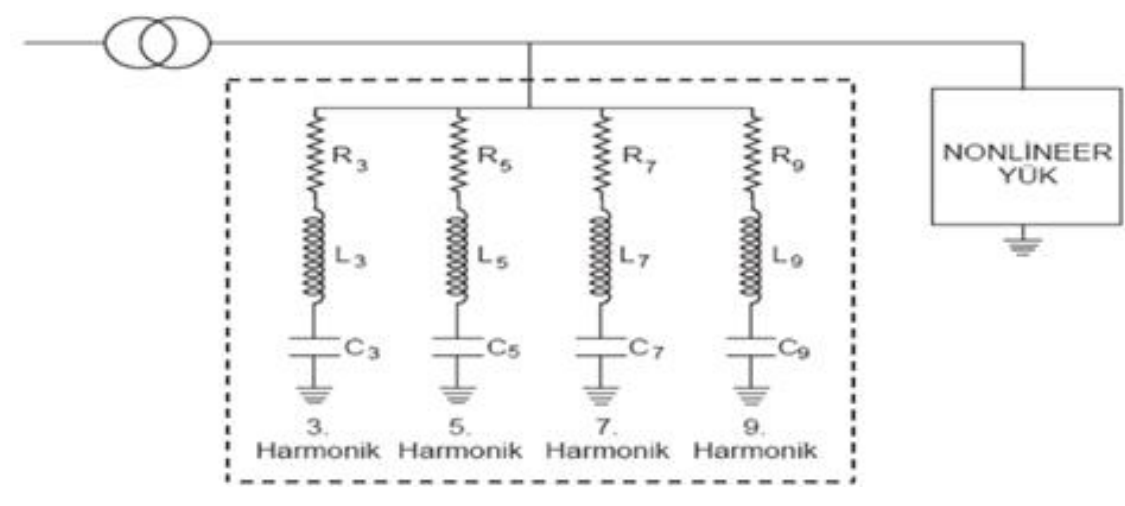

Şekil 6. Bir devrede pasif filtrenin kullanılması

\section{Filtre Uygulamaları}

$\mathrm{Bu}$ bölümde endüstriyel tesislerde kullanılan güç elektroniği çeviricilerinin ürettiği harmoniklerin filtrelenmesi gerçekleştirilecektir. İki farklı güç elektroniği çeviricisi yapısına yine iki farklı filtre çeşidi uygulanacak ve sonuçlar gözlenecektir. 


\subsection{Pasif Filtre Uygulaması}

$\mathrm{Bu}$ bölümde sanayide kullanılan ve gerilimi $100 \mathrm{KV}$, gücü $50 \mathrm{MW}$ olan 6-darbeli bir güç elektroniği çeviricisinin temel frekans $50 \mathrm{~Hz}$ olan sistemde filtreleme işlemi, 13. Harmoniğe kadar tek ayarlı filtre ile 17. Harmonik ve üzerindekiler için ikinci dereceden sönümlü filtre ile yapılacaktır. 30MVAr'lık kondansatör grubu için kalite faktörünü 40 alarak filtre elemanları belirlenmiştir.

6- darbeli güç elektroniği çeviricisi gerilimi

$$
\begin{aligned}
(w t) & =100000 \sin w t+30000 \sin 5 w t+20000 \sin 7 w t+12000 \sin 11 w t \\
& +5000 \sin 13 w t+1000 \sin 17 w t \ldots \quad[V]
\end{aligned}
$$

olmak üzere tasarlanan filtrenin L, C, R değerleri Ek 1'de verilen MATLAB koduyla hesaplanmıştır. Buna göre, filtredeki her bir kondansatörün kapasite değeri

$$
\mathrm{C}=1.90986 \mathrm{e}-006 \mathrm{~F}
$$

ve endüktans değerleri

L_5 $=0.212 \mathrm{H}, \quad \mathrm{L} \_7=0.108 \mathrm{H}, \quad \mathrm{L} \_11=0.044 \mathrm{H}, \quad \mathrm{L} \_13=0.031 \mathrm{H}, \quad \mathrm{L} \_17=0.018 \mathrm{H}$

olarak hesaplanmıştır.

Filtredeki direnç değerleri ise

$$
\text { R_5 }=8.333 \Omega, \text { R_7 }=5.952 \Omega, \text { R_11=3.788 } \Omega, \text { R_13=3.205 } \Omega, \text { R_17=98.039 } \Omega
$$

olarak bulunmuştur.

PSPICE platformu altında elde edilen 6- darbeli güç elektroniği çeviricisine ait filtreleme öncesi gerilim işareti Şekil 7'de verilmiştir. Şekil 8'de 6-darbeli güç elektroniği çeviricisine ait gerilimin harmonik spektrumu, şekil 9'da filtreden önceki akım ve şekil 10'da filtreden önceki akımın harmonik spektrumu görülmektedir. PSPICE ile yapılan Fourier analizinden işaretin THDv'si \% 38,05644 olarak hesaplanmış, THDi ise \% 124,9433 olarak hesaplanmıştır.

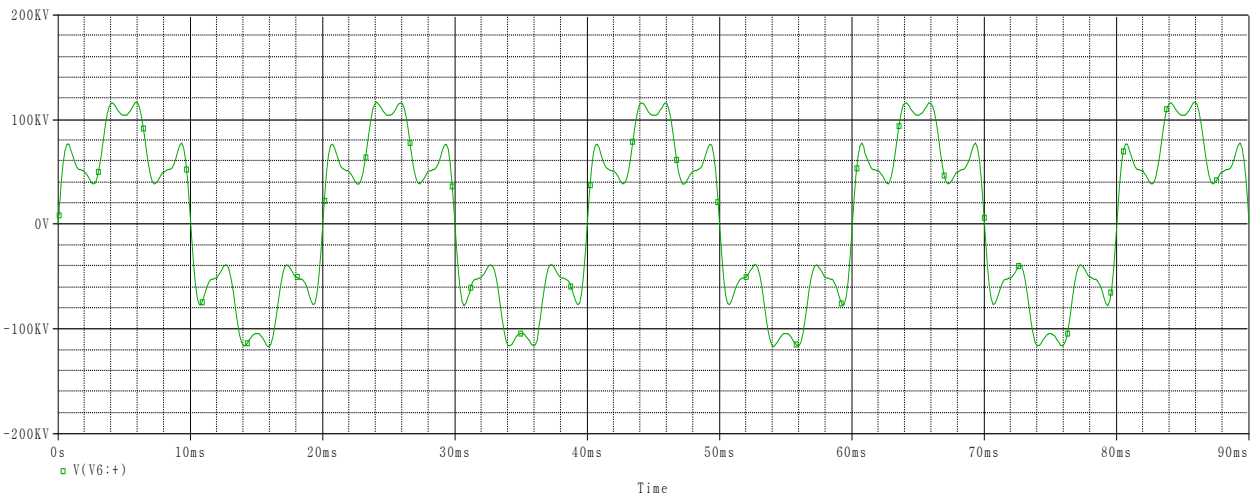

Şekil 7. Filtrelenmeden önceki 6-darbeli güç elektroniği çeviricisi gerilimi

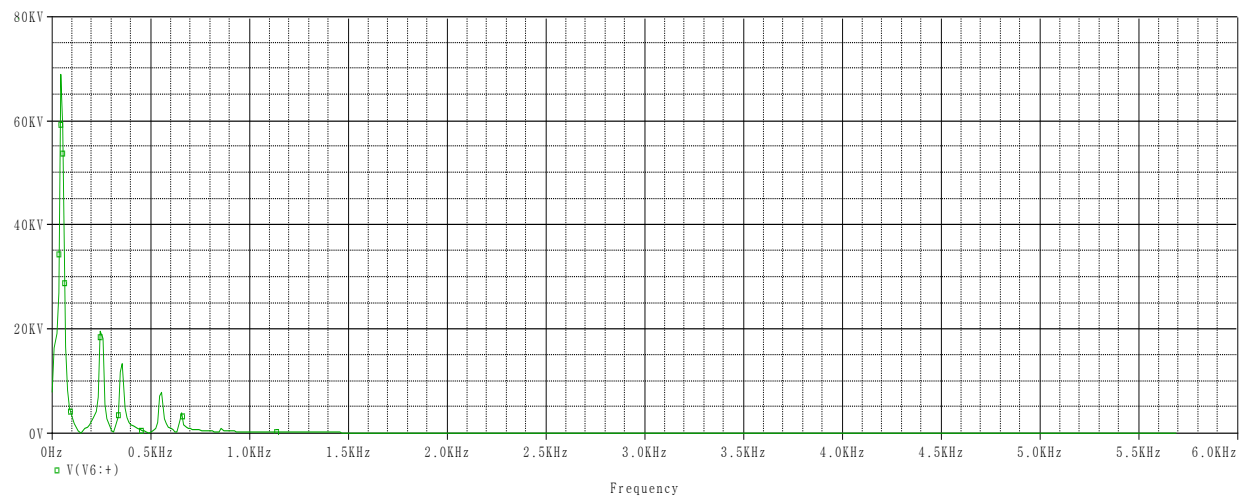

Şekil 8. Filtrelenmeden önceki 6-darbeli güç elektroniği çeviricisi geriliminin harmonik spektrumu 


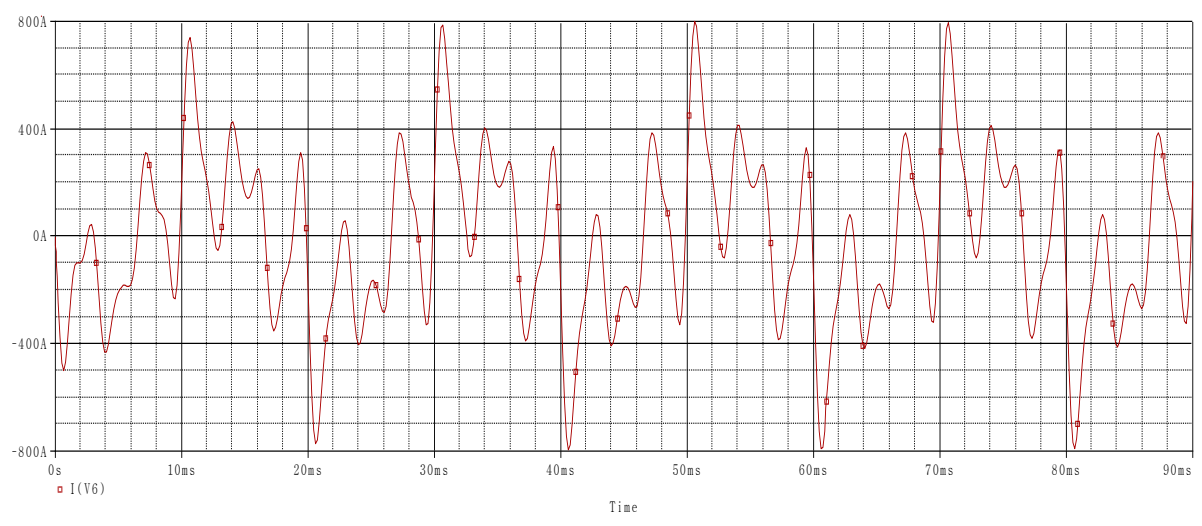

Şekil 9. Filtrelemeden önceki akım işareti

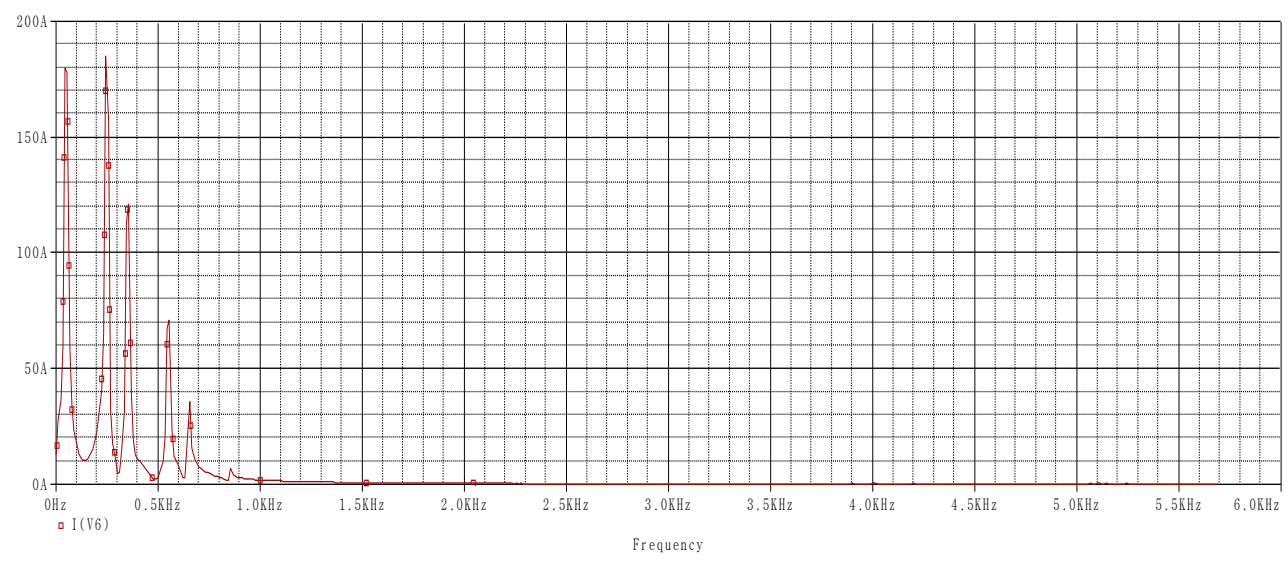

Şekil 10. Filtrelemeden önceki akımın harmonik spektrumu

6-darbeli güç elektroniği çeviricisi geriliminin harmoniklerine göre pasif filtre tasarımı yapılmış ve filtreden sonra elde edilen işaretler aşağıda gösterilmiştir. İstenilen Q'ya (kalite faktörüne) ve filtrede kullanılacak Qc'ye (kapasitör büyüklüğü) göre filtre elemanları MATLAB kodu ile hesaplatılmıştır. Tasarlanan filtre PSICE kodu ile yazılmış ve güç elektroniği çeviricisi geriliminin çıkışına bağlanmıştır. Şekil 11'de fitreden sonraki 6- darbeli güç elektroniği çeviricisinin gerilim işareti gösterilmiştir. Şekil 12 'de filtreden sonraki 6-darbeli gerilim işaretinin harmonik spektrumu gösterilmiştir. Şekil 13' de filtreden sonraki akım işareti ve şekil 14'te filtreden sonraki akımın harmonik frekansı görünmektedir. PSPICE ile yapılan fourier analiz sonucunda filtreden sonra hesaplatılan THDv değerinin $\% 3.74587$ olduğu hesaplanmış ve THDi ise \% 3.74587 olarak hesaplanmıştır. Bu değerler, toplam harmonik bozunumlardaki düzelmeyi göstermektedir.

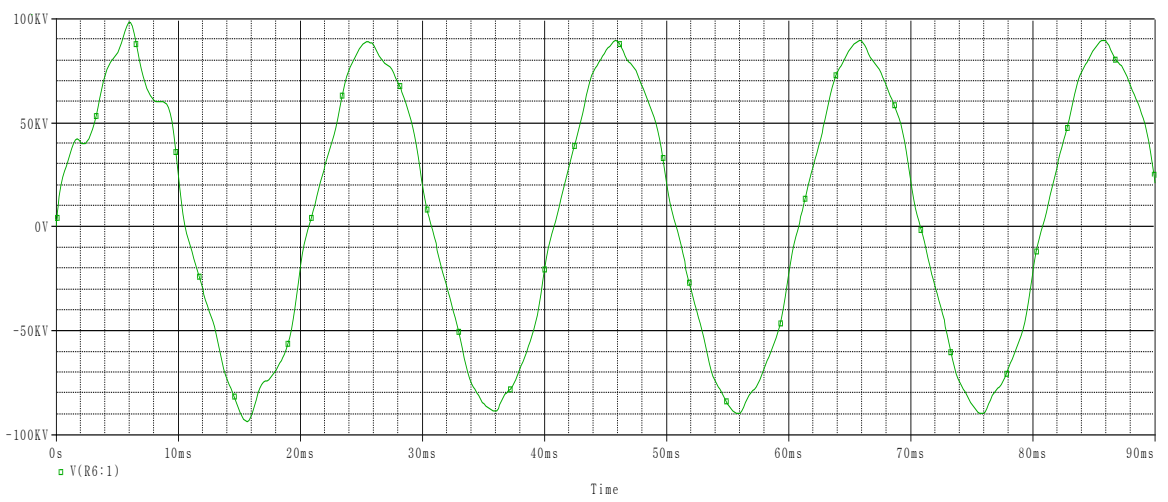

Şekil 11. Filtreden sonraki 6-darbeli güç elektroniği çeviricisi gerilimi işareti 


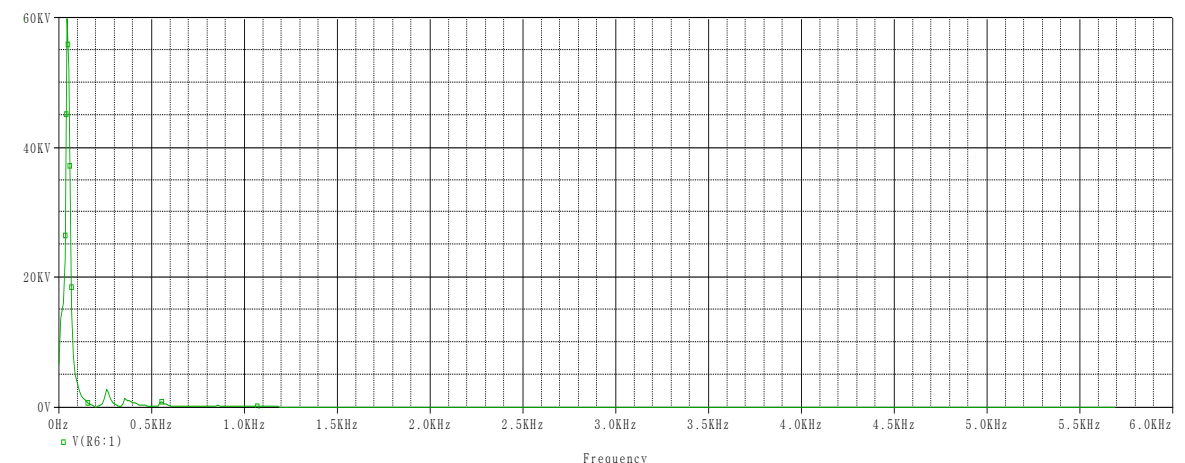

Şekil 12. Filtreden sonraki 6-darbeli güç elektroniği çeviricisi geriliminin harmonik spektrumu

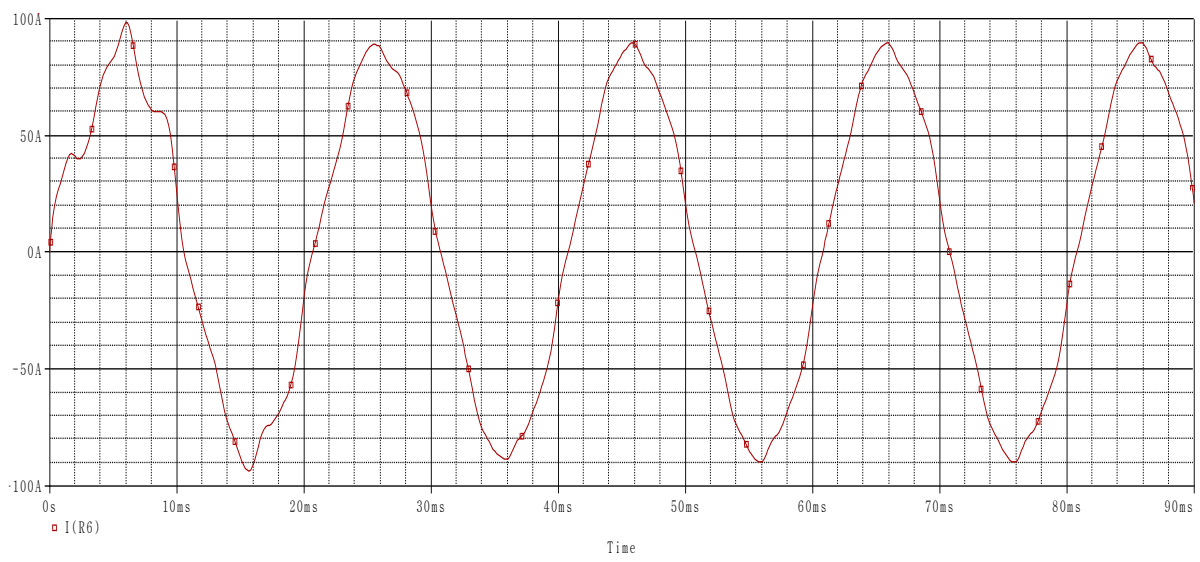

Şekil 13. Filtreden sonraki akım işareti

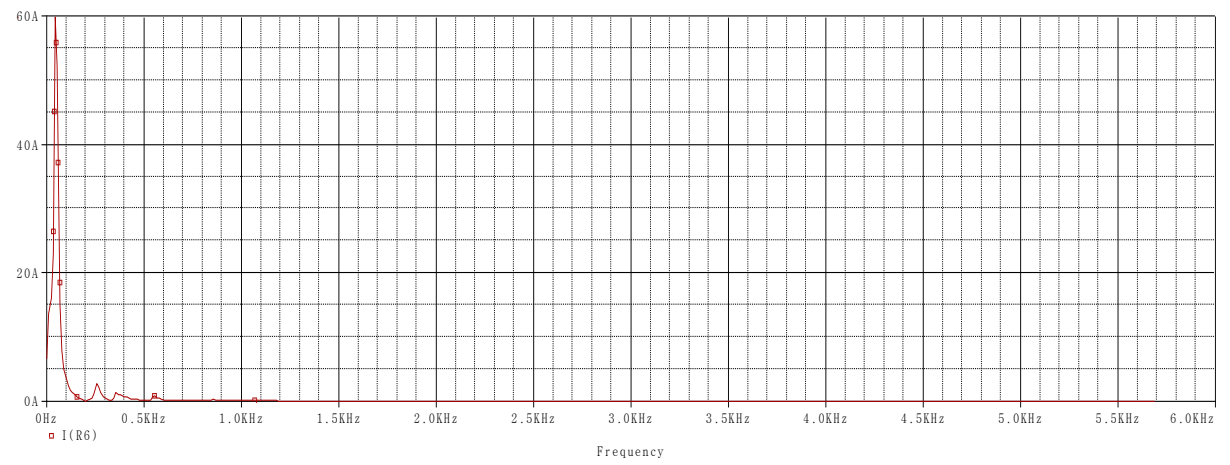

Şekil 14. Filtreden sonra akımın harmonik spektrumu

\subsection{Aktif Filtre Uygulaması}

Aktif filtrelerin incelenmesi uygulamasında 12-darbeli bir konvertörde oluşan akım verilmiş ve bu harmonikli akım için tasarlanacak aktif filtre akımı bulunmuştur. Önceki bölümde de bahsedildiği gibi aktif filtrede amaç harmonik bileşiklerle aynı frekansta ve genlikte bir ters akım sağlayarak harmonikleri yok etmektir. Akımı

$i(w t)=50 \sin w t-4 \sin 11 w t+2.6 \sin 13 w t-1.8 \sin 23 w t+1.2 \sin 25 w t \quad[A]$

olan 12-darbeli bir güç elektroniği çeviricisinin nonsinüsoidal yük akımından temel bileşen akımının çıkarılması ile aktif filtre akımı belirlenir

$\dot{\mathrm{I}}_{A}=\dot{\mathrm{I}}_{S}-\dot{\mathrm{I}}_{1}=\dot{\mathrm{I}}-\dot{\mathrm{I}}_{1}=4 \sin 11 w t-2.6 \sin 13 w t+1.8 \sin 23 w t-1.2 \sin 25 w t \quad[A]$ 
$\dot{\mathrm{I}}_{H}$ : aktif filtre akımı

$\dot{\mathrm{I}}_{S}$ : şebeke akımı

olarak elde edilir. Böylece şebekeden çekilecek akım

$\dot{\mathrm{I}}_{S}=\dot{\mathrm{I}}_{1}+\dot{\mathrm{I}}_{H} 50 \sin w t$

olarak hesaplanır.

Aktif filtrede amaç harmoniklerle aynı frekansta ve genlikte bir ters işaret üretip devreye vermektir. Problemin çözümünde de bu yol izlenmiştir.

Yapılan bu işlemler Ek B'de verilen MATLAB kodu ile gerçeklenmiştir. Şekil 15'te 12 darbeli güç elektroniği çeviricisinin akımı, aktif filtre akımı ve filtreden sonraki akım gösterilmiştir.
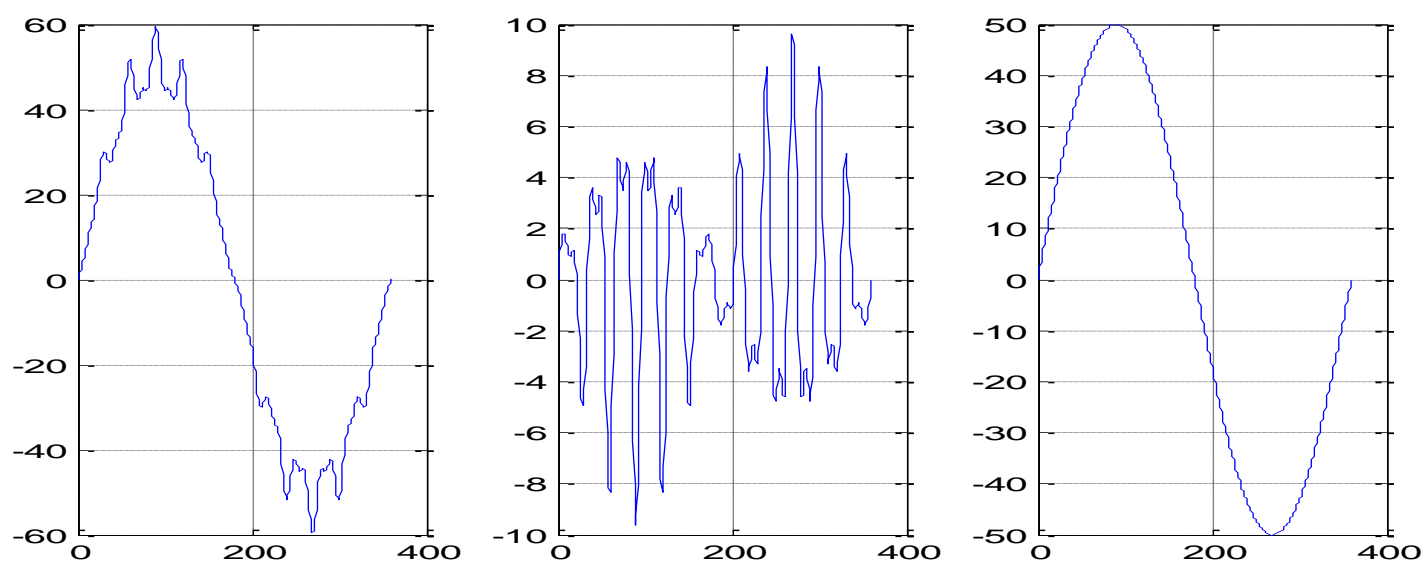

Şekil 15. 12-Darbeli güç elektroniği çeviricisi akımı, aktif filtre akımı ve filtreden sonraki 12- darbeli güç elektroniği çeviricisi akımı

Tablo 1. Filtreleme öncesi ve sonrası bozunum seviyelerinin karşılaştırılması

\begin{tabular}{|c|c|c|c|}
\hline \multicolumn{2}{|c|}{ Akım için toplam harmonik bozunum seviyesi } & \multicolumn{2}{|c|}{$\begin{array}{c}\text { Gerilim için toplam harmonik bozunum seviyesi } \\
(\%)\end{array}$} \\
\hline Filtreleme öncesi & Filtreleme sonras1 & Filtreleme öncesi & Filtreleme sonras1 \\
\hline 124 & 3,7 & 38 & 3,7 \\
\hline
\end{tabular}

\section{Sonuç ve Tartışma}

Enerji kalitesinin sağlanmasında harmonikler, güç katsayısı, gerilim ve akım değerlerindeki darbeler, değer değişiklikleri, dalgalanmalar ve fliker (gerilim titreşmesi) en büyük bozucu parametrelerdir. Enerji kalitesini doğrudan etkileyen bu etmenler ürün ve üretim kalitesini de etkilemektedir.

Harmoniklerin varlığı, elektrik sistemlerinin çalışmayacağı anlamına gelmez. Diğer güç kalitesi olayları gibi, harmoniklerin varlığında da çalışmanın sürekliliği, güç iletim sisteminin sağlamlığına ve donanım hassasiyetine bağlıdır. Dolayısıyla tasarım aşamasında bu hassasiyetler göz önüne alınıp tasarımın yapılması atılması gereken ilk adımdır.

Yarı iletken elemanların tabiatı gereği ve sanayide kullanılan nonlineer yüklerin (transformatör, ark firınları vb.) etkisiyle; akım ve gerilim dalga biçimleri, periyodik olmakla birlikte sinüsoidal dalga ile frekans ve genliği farklı diğer sinüsoidal dalgaların toplamından meydana gelmektedir. 
Güç kalitesi için risk kaynağı olan bu konunun; yüksek tasarım uygulamaları yapılarak, doğru seçilmiş elektrik cihazları kullanılarak, uygun bakım prosedürleri geliştirilerek, gerekli yatırımlar yapılarak kontrol altında tutulması ve iyileştirilmesi gerekmektedir [1,2].

Şebekedeki harmonik akımlar şebeke empedansı üzerinde gerilim düşümü meydana getirir ve gerilim dalgasının formu bozulur, kayıplar artar ve şebekede kullanılan cihazlarda olumsuzluklar meydana gelir. Bu olumsuz etkiler, harmonik kaynakların sistemdeki yerine, iletim ve dağıtım sistemlerindeki yayılımına ve şebeke karakteristiklerine bağlıdır. Güç sistemlerinde oluşan harmoniklerin şebeke cihazlarına zarar vermemesi için oluşan harmoniklerin süzülmesi gerekir.

$\mathrm{Bu}$ çalışmada harmonik kaynaklarından güç elektroniği çeviricilerinin çalışması esnasında ortaya çıkan harmoniklerin filtrelenmesi amaçlanmıştır. Filtre uygulanmadan önceki gerilim için toplam harmonik bozunum (THDv) \%38 seviyelerinde iken, filtreden sonraki gerilimin toplam harmonik bozunumu (THDv) \%3,7 seviyelerine düşmüştür. Benzer şekilde, akım için toplam harmonik bozunum (THDi) değeri de \%124 seviyesinden \% 3,7 seviyesine düşürülmüştür.

\section{Kaynaklar}

1. Efe, S.B. 2010. Güç Sistemlerinde Harmonikler ve Harmoniklerin Engellenmesi, EMO Diyarbakır Şube Bülteni, 19-23.

2. Efe, S.B. 2007. Güç Sistemlerinde Harmonikler ve Harmoniklerin Analizi (yüksek lisans tezi). İnönü Üniversitesi, Fen Bil. Ens., Elektrik Elektronik Mühendisliği Anabilim Dalı, 1-57.

3. Rüstemli S., Cengiz, M.S., Dinçer, F. 2013. Elektrik Tesislerinde Harmoniklerin Aktif Filtre Kullanılarak Yok Edilmesi ve Simülasyonu, BEÜ Fen Bilimleri Dergisi, 2 (1): 30-38.

4. Rüstemli S., Cengiz M.S. 2015. Active Filter Solutions in Energy Systems, Turkish Journal of Electrical Engineering \& Computer Sciences, DOI: 10.3906/elk-1402-212.

5. Yacamini R. 1994. Power System Harmonics, IEEE Power Eng. Journal, 8 (4): 193-198..

6. Dumitrescu A.M., Griva G., Bojoi R., Bostan V., Magureanu ,R. 2009. Current controllers design using Naslin polynomal method for Active Power Filters , Electrotechn. et. Energ., 54 (1): 115124.

7. Salemon P. Litran S.P. 2010. Improvement of the Electric Power Quality Using Series Active and Shunt Passive Filters, IEEE Trans. Power Del. 25 (2): 1058-1067.

8. Rüstemli S., Okuducu, E., Efe, S.B. 2015. Elektrik Tesislerinde Harmoniklerin Pasif Filtre Kullanılarak Azaltılması ve Simülasyonu, EVK2015: 6. Enerji Verimliliği, Kalitesi Sempozyumu, pp120-124, 4-6 Haziran, Sakarya. 


\section{EK A}

6-Darbeli Güç Elektroniği Çeviricisine Ait Pasif Filtre Tasarımının Matlab Kodu

\% 6-darbeli güç elektroniği çeviricisine aitfiltretasarımmatlabkodu

clear

clc

$\mathrm{f}=50 ; \%$ Frekans $[\mathrm{Hz}]$

$\mathrm{w}=2 * \mathrm{pi} * \mathrm{f}$

$\mathrm{V}=100 \mathrm{e} 3 ; \%$ Güç elektroniği çeviricisi Gerilimi [V]

$\mathrm{Qc}=30 \mathrm{e} 6 \%$ \% TasarlancakFiltreGücü [VAr]

$\mathrm{Q}=40 ; \%$ KaliteFaktörü

\% 6-Darbeli Güç elektroniği çeviricisininHarmonikBilesenleri

$\mathrm{n}=\left[\begin{array}{lllll}5 & 7 & 11 & 13 & 17\end{array}\right]$

$\mathrm{Ct}=\mathrm{Qc} /\left(\mathrm{w}^{*} \mathrm{~V}^{\wedge} 2\right)$;

$\%$ Filtrenin 5 paralelkoluvardir,

$\%$ Herbirparalelkoldakikond.kapasitesi

$\mathrm{C}=\mathrm{Ct} / 5$;

fori $=1: 4$

$\%$ Rezonanstareaktansdegeri

$\mathrm{Xr}(\mathrm{i})=1 /\left(\mathrm{n}(\mathrm{i}) * \mathrm{w}^{*} \mathrm{C}\right)$;

$\%$ Filtredekidirençdegeri

$\mathrm{R}(\mathrm{i})=\mathrm{Xr}(\mathrm{i}) / \mathrm{Q}$;

$\%$ Endüktansdegeri

$\mathrm{L}(\mathrm{i})=\mathrm{Xr}(\mathrm{i}) /\left(\mathrm{n}(\mathrm{i})^{*} \mathrm{w}\right)$;

end

$\mathrm{f} 0=\mathrm{n}(5) * 50$;

$\mathrm{R} 17=1 /(2 * \mathrm{pi} * \mathrm{C} * \mathrm{f} 0)$;

$\mathrm{m}=1$;

$\mathrm{L} 17=\mathrm{m} * \mathrm{R} 17^{\wedge} 2 * \mathrm{C}$;

$\%$ Sonuçlar

disp('Filtredekiherbirkond.ünkapasitedeðeri');

fprintf('C $=\% \mathrm{~g}[\mathrm{~F}] \backslash \mathrm{n}$ ', C);

fprintf('In Filtredekiendüktansdeðerleriln');

fprintf(' L5 $\quad$ L7 $\quad$ L11 $\quad$ L13 $\quad$ L17 [H] $\backslash n ')$;

fprintf('====================================ไn');

fprintf('\%6.3f \%6.3f \%6.3f \%6.3f \%6.3fn',,...

L(1),L(2),L(3),L(4),L17);

fprintf('In Filtredekidirençdeðerleri\n');

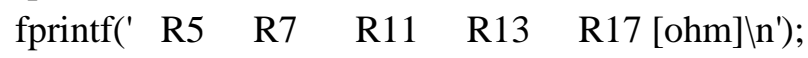

fprintf('===========================================!n');

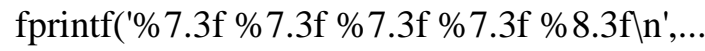

$\mathrm{R}(1), \mathrm{R}(2), \mathrm{R}(3), \mathrm{R}(4), \mathrm{R} 17)$; 


\section{EK B}

\section{Aktif Filtre İçin Matlab Kodu}

\% 12-darbeli birgüç elektroniği çeviricisininakımı

clear

clc

\%Derecedenradyanadönüstürme

$\mathrm{d}=\mathrm{pi} / 180$;

$\mathrm{wt}=0: 360$;

\% 12-darbeli birgüç elektroniği çeviricisininakımı

$\mathrm{i}=50 * \sin (\mathrm{wt} * \mathrm{~d})-4 * \sin \left(11^{*} \mathrm{wt} * \mathrm{~d}\right)+2.6 * \sin \left(13^{*} \mathrm{wt} * \mathrm{~d}\right) \ldots$

$-1.8 * \sin (23 * \mathrm{wt} * \mathrm{~d})+1.2 * \sin (25 * \mathrm{wt} * \mathrm{~d})$;

$\%$ Filtreakım

$\mathrm{iH}=4 * \sin \left(11^{*} \mathrm{wt} * \mathrm{~d}\right)-2.6 * \sin (13 * \mathrm{wt} * \mathrm{~d})+1.8 * \sin (23 * \mathrm{wt} * \mathrm{~d}) \ldots$

$-1.2 * \sin (25 * \mathrm{wt} * \mathrm{~d})$

$\%$ sebekedençekilecekakım

$\mathrm{iS}=\mathrm{i}+\mathrm{iH}$;

\% 12-darbeli bir güç elektroniği çeviricisi akımınındalgaseklininçizimi subplot $(1,3,1)$

$\operatorname{plot}(w t, i)$

grid

holdon

$\%$ Filtreakımınındalgaseklininçizimi

subplot $(1,3,2)$

$\operatorname{plot}(\mathrm{wt}, \mathrm{iH})$

grid

holdon

$\%$ sebekedençekilenakımındalgaseklininçizimi

$\operatorname{subplot}(1,3,3)$

$\operatorname{plot}(w t, i S)$

grid

holdon 